\title{
Efeito de inoculante ectomicorrízico produzido por fermentação semi-sólida sobre o crescimento de Eucalyptus dunnii Maiden ${ }^{(1)}$
}

\author{
João Rogério Alves ${ }^{(2)}$, Ozair de Souza(3), Pablo Angel Sanchez Podlech(4), \\ Admir José Giachini ${ }^{(5)}$ e Vetúria Lopes de Oliveira ${ }^{(5)}$
}

\begin{abstract}
Resumo - O crescimento de Eucalyptus é favorecido por fungos ectomicorrízicos (FECM). De ocorrência comum nas plantações florestais, os FECM diferem, entretanto, em infectividade e eficiência. $\mathrm{O}$ objetivo deste estudo foi testar a compatibilidade e a eficiência do inoculante ectomicorrízico produzido por fermentação semi-sólida, em relação a Eucalyptus dunnii Maiden. Neste sentido, o inoculante de Pisolithus sp., produzido por fermentação semi-sólida em vermiculita-solução nutritiva, foi aplicado ao substrato turfa-vermiculita (30:70, v/v) nas concentrações de $0,1,3,5$ e 10\% (v/v) que foi semeado com E. dunnii, e mantido em casa de vegetação. A inoculação proporcionou colonização radicular e aumento da matéria seca da parte aérea e do conteúdo de $\mathrm{P}$ em razão da concentração do inoculante. O peso da matéria seca das plantas com $1 \%$ de inoculante não diferiu do peso das testemunhas. A $3 \%$ e $5 \%$, a matéria seca aumentou $62 \%$. O maior valor foi obtido com $10 \%$ de inoculante, onde o peso das plantas foi $73 \%$ superior ao das testemunhas, e o teor de $\mathrm{P}, 130 \%$. Resultados semelhantes foram obtidos em relação à raiz. Altura e diâmetro foram positivamente afetados pela inoculação, mas não a relação raiz/parte aérea. As doses mais eficientes de inoculante foram aquelas de $3 \%$ ou superiores. Este método de produção deverá ser testado com outros FECM, e sua eficiência, avaliada em viveiro e no campo.
\end{abstract}

Termos para indexação: Pisolithus, inoculação, eficácia, fósforo, absorção.

\section{Effect of ectomycorrhizal inoculum produced \\ by solid state fermentation on growth of Eucalyptus dunnii Maiden}

\begin{abstract}
Growth of Eucalyptus can be improved by ectomycorrhizal fungi (ECMF). Although widespread in forest plantations, ECMF differ in infectivity and effectiveness, hence the need of selection of compatible and efficient ECMF and the establishment of inoculum production methods. The objective of this study was to test compatibility and efficiency of the ectomycorrizal inoculum produced by solid state fermentation, in relation to Eucalyptus dunnii Maiden. For this purpose, inoculum of Pisolithus sp. was produced by solid state fermentation in vermiculite + nutrient solution and applied to peat:vermiculite $(30: 70 \mathrm{v} / \mathrm{v})$ at $0,1,3,5$ and $10 \%(\mathrm{v} / \mathrm{v})$. Seeds of $E$. dunnii were sown and kept in a glasshouse. Inoculation promoted root colonization, plant growth and phosphorus $(\mathrm{P})$ uptake depending upon inoculum concentration. Plant dry matter with $1 \%$ inoculum did not differ from that of the controls. At $3 \%$ and $5 \%$, plants had $60 \%$ more dry matter than the controls. At $10 \%$, inoculum shoot dry weight (dw) was $70 \%$ higher, and P content was $130 \%$ higher than that of the controls. Similar results were obtained in relation to root dw. Height and diameter were also positively affected by inoculation. Root:shoot ratios were not influenced. The most efficient doses were those at 3\% inoculum or higher. This method of inoculum production needs to be tested with other ECMF and its efficiency must be evaluated in the nursery and in the field.
\end{abstract}

Index terms: Pisolithus, inoculation, efficiency, phosphorus, absorption.

(1) Aceito para publicação em 9 de maio de 2000.

Financiado pelo PADCT (MCT), Subprograma de Biotecnologia (SBIO-01/95-02).

(2) Universidade Federal de Santa Catarina (UFSC), Dep. de Microbiologia e Parasitologia, Caixa Postal 476, CEP 88040-900 Florianópolis, SC. Bolsista CNPq.

E-mail: jralves@agricultura.sc.gov.br
(3) Universidade de Joinville, Dep. de Química Industrial, Caixa Postal 1361, CEP 89201-972 Joinville, SC.

E-mail: souzaoz@zaz.com.br

(4) Universidade do Vale do Itajaí, Curso de Farmácia, Centro de Saúde, Rua Uruguai, 458, CEP 88302-202 Itajaí, SC.

E-mail: pablo@netville.com.br

${ }^{(5)}$ UFSC, Dep. de Microbiologia e Parasitologia.

E-mail: giachina@ucs.orst.edu, veturia@mbox1.ufsc.br 


\section{Introdução}

O Brasil apresenta o maior programa de reflorestamento do mundo ( $c a .6$ milhões ha). Espécies dos gêneros Eucalyptus e Pinus são as mais importantes nesse programa (Lima, 1993; Sociedade Brasileira de Silvicultura, 1994). A partir dos anos 60, os eucaliptos passaram a ser intensivamente utilizados nas regiões Sul e Sudeste.

Como o déficit mundial de madeira até 2010 será da ordem de 500 milhões de $\mathrm{m}^{3}$ ano $^{-1}$ (Sociedade Brasileira de Silvicultura, 1997), o Brasil deverá aumentar sua produção para atender à demanda. Para isso, é necessário melhorar a produtividade, pois o aumento da área plantada é inviável diante das atuais limitações financeiras, políticas e ambientais (Alvarenga, 1994). Tecnologias alternativas deverão ser adotadas, para o aumento da produtividade. Entre elas, encontra-se a inoculação com fungos micorrízicos selecionados, favorecendo o crescimento das plantas mesmo em solos com baixos teores de nutrientes.

O termo micorriza (Frank, 1885) denomina uma associação altamente especializada entre raízes e certos fungos do solo. Essas associações melhoram a capacidade de absorção e utilização dos nutrientes (Bougher et al., 1990; Thomson et al., 1994), de absorção de água (Levy \& Krikun, 1980), de tolerância a condições desfavoráveis do solo (Wilkins, 1991) e de resistência a microrganismos patogênicos ou deletérios (Marx, 1969; Kope \& Fortin, 1989; Newsham et al., 1995).

As micorrizas são classificadas em cinco tipos, de acordo com a estrutura e os simbiontes envolvidos: micorrizas vesículo-arbusculares, ectomicorrizas, ectendomicorrizas, micorrizas orquidóides, micorrizas ericóides e micorrizas monotropóides (Smith \& Read, 1997). As ectomicorrizas predominam em plantas das seis famílias mais utilizadas em silvicultura no mundo. Três dessas famílias (Fagaceae, Pinaceae e Myrtaceae) são objeto de técnicas intensivas de cultivo. Embora freqüentes nessas plantações florestais, os fungos ectomicorrízicos variam em compatibilidade e eficiência, dependendo das espécies simbiontes e das condições ambientais (Garbaye, 1990; Smith \& Read, 1997), exigindo estudos prévios para detectar as melhores combinações fungo-hospedeiro-ambiente. Assim, o controle dessas combinações, denominado "controle da micorrização" (Garbaye, 1984), pode melhorar a produtividade das plantações. Resultados expressivos têm sido obtidos pelo controle da micorrização em diferentes países, mostrando seu grande potencial para o setor florestal (Garbaye, 1990).

O controle da micorrização exige o desenvolvimento de métodos de produção de inoculantes em larga escala (Hung \& Molina, 1986; Garbaye, 1990). Vários tipos de inoculantes ectomicorrízicos têm sido utilizados, destacando-se os esporos (Theodorou \& Benson, 1983; Marx et al., 1989b) e o inoculante vegetativo, constituído do micélio em cultura pura numa mistura vermiculita-turfa-meio de cultura (Marx et al., 1982; Last et al., 1984). O inoculante vegetativo permite a utilização de fungos previamente testados quanto à infectividade e eficiência no crescimento do hospedeiro (Marx, 1980; Marx et al., 1989a). Além disso, o micélio fica protegido entre as lâminas de vermiculita, e o fungo pode sobreviver até a emissão de raízes receptivas (Garbaye, 1990; Smith \& Read, 1997).

Com este método, os fungos Pisolithus tinctorius (Marx et al., 1989a), Hebeloma crustuliniforme e Laccaria laccata (Hung \& Molina, 1986; Castellano \& Molina, 1989) têm sido extensivamente inoculados nas mudas de Pinus spp. e Pseudotsuga menziesii nos EUA. Outro exemplo é o inoculante de $L$. laccata, comercializado na França por uma indústria de inoculantes de fungos comestíveis (Garbaye, 1990).

Uma técnica mais sofisticada consiste no cultivo do fungo via fermentação líquida e encapsulamento do micélio em alginato de cálcio, com base na técnica de imobilização de rizóbios proposta por Dommergues et al. (1979). Em viveiros, inoculantes de diferentes FECM produzidos por este método foram eficientes na colonização e promoção do crescimento de diferentes hospedeiros (Le Tacon et al., 1985; Maupérin et al., 1987; Kropácek et al., 1990; Kuek et al., 1992). O micélio encapsulado pode sobreviver mais tempo no solo, e é de fácil armazenamento e transporte e de maior viabilidade, reduzindo, dessa forma, a quantidade a ser empregada (Kuek et al., 1992). No entanto, o método encontra-se ainda em processo experimental, mesmo após 
mais de uma década de estudos. Dificuldades na multiplicação dos fungos por fermentação líquida, devidas às contaminações freqüentes, comprometem a qualidade do inoculante, sobretudo na produção em larga escala (Šašek, 1990). As operações de lavagem e imobilização do micélio representam mais riscos de contaminação, aumentando os custos do processo (Marx et al., 1989a; Garbaye, 1990).

O controle da micorrização exige, portanto, que a seleção de fungos seja seguida por mais estudos, para estabelecer métodos de produção de inoculantes de alta qualidade, estabilidade, e de baixo custo.

O objetivo deste estudo foi testar a compatibilidade e eficiência de inoculante ectomicorrízico, produzido por fermentação semi-sólida, em relação a Eucalyptus dunnii Maiden.

\section{Material e Métodos}

Foi empregado o isolado fúngico ectomicorrízico UFSC-Pt24 (Pisolithus sp.), da coleção do Laboratório de Ectomicorrizas do Departamento de Microbiologia e Parasitologia da Universidade Federal de Santa Catarina. O isolado foi obtido de frutificações colhidas em plantações de Eucalyptus sp. no Estado de Santa Catarina.

Culturas do isolado foram mantidas em meio de cultura sólido MNM-extrato de levedura [modificação do meio MNM (Marx, 1969), pela adição de $3 \mathrm{~g}$ de extrato de levedura $\mathrm{L}^{-1}$ ] (Pradella et al., 1991), incubadas na ausência de luz, à temperatura de $30 \pm 1^{\circ} \mathrm{C}$ em incubadora BOD, com transferências quinzenais para meio fresco de igual composição. Para inocular o substrato de fermentação, o fungo foi cultivado em meio MNM-extrato de levedura líquido, em frascos de $1.000 \mathrm{~mL}$ a $30 \pm 1^{\circ} \mathrm{C}$. Cada frasco recebeu dois discos de micélio $(\varnothing=8 \mathrm{~mm})$ provenientes das culturas em meio sólido. Após 15 dias de incubação sob agitação contínua e ausência de luz, o micélio foi triturado assepticamente, e utilizado para inocular o substrato de fermentação.

A fermentação foi realizada conforme o método descrito por Souza (1996). Como substrato, empregou-se vermiculita (tamanho médio), previamente esterilizada em autoclave $\left(120^{\circ} \mathrm{C}\right)$, duas vezes por $60 \mathrm{~min}$, com intervalo de 24 horas. Após a esterilização, foi adicionado meio líquido MNM-extrato de levedura (sem tiamina), $\mathrm{pH} 4,5$, de modo a obterem-se as seguintes concentrações ( $\mathrm{g} \mathrm{kg}^{-1}$ de vermiculita): glicose, 240; extrato de levedura, 24; extrato de malte, 24; $\left(\mathrm{NH}_{4}\right)_{2} \mathrm{HPO}_{4}, 2 ; \mathrm{KH}_{2} \mathrm{PO}_{4}, 1,2$; $\mathrm{CaCl}_{2} \cdot 2 \mathrm{H}_{2} \mathrm{O}, 0,6 ; \mathrm{NaCl}, 0,2 ; \mathrm{FeCl}_{3}, 0,1$, procedendo-se à distribuição em embalagens de polipropileno $(30 \times 20 \mathrm{~cm})$ com $300 \mathrm{~mL}$ de meio e $50 \mathrm{~mL}$ de vermiculita por embalagem. Após mistura do meio com a vermiculita, o pH final do meio foi de 5,8. Esse substrato foi inoculado com $30 \mathrm{~mL}$ de suspensão de micélio triturado, previamente produzido em meio MNM-extrato de levedura líquido sob as condições descritas anteriormente. A fermentação ocorreu sob condições de temperatura controlada a $30 \pm 1^{\circ} \mathrm{C}$, na obscuridade, durante 60 dias, quando o micélio completou a colonização do substrato.

Sementes de E. dunnii foram desinfectadas em álcool $(70 \%)$ e germinadas em uma solução contendo $\mathrm{CaSO}_{4} \cdot 2 \mathrm{H}_{2} \mathrm{O}\left(0,068 \mathrm{~g} \mathrm{~L}^{-1}\right), \mathrm{H}_{3} \mathrm{BO}_{3}\left(0,168 \mathrm{~g} \mathrm{~L}^{-1}\right)$, glicose anidra $\left(2 \mathrm{~g} \mathrm{~L}^{-1}\right), \mathrm{pH} 5,7$ (Thomson et al., 1994), sob aeração forçada, durante três dias, à temperatura ambiente. Após esse período, foram retiradas da solução, lavadas em água destilada esterilizada, e transferidas para o substrato de plantio.

O substrato de plantio constou de uma mistura turfavermiculita $(30: 70, \mathrm{v} / \mathrm{v})$ previamente esterilizada $\left(120^{\circ} \mathrm{C}\right.$, durante $60 \mathrm{~min}$ ), suplementada com o inoculante fúngico e distribuída em tubetes plásticos de forma cônica com $60 \mathrm{~mL}$ de volume. A homogeneização da mistura foi feita sob condições assépticas. A esse substrato foi incorporado adubo de liberação lenta (Nutricote ${ }^{\circledR}, 0,25$ g tubete $^{-1}$ ) com a seguinte composição em nutrientes: 14-8-8 (N-P-K) e $2 \%$ de $\mathrm{MgO}, 0,15 \%$ de $\mathrm{Fe}, 0,06 \%$ de $\mathrm{Mn}, 0,05 \%$ de $\mathrm{Cu}$, $0,02 \%$ de B, $0,02 \%$ de Mo e $0,015 \%$ de Zn.

Antes de ser adicionado ao substrato de plantio, o inoculante foi lavado três vezes com água destilada esterilizada, para retirada dos nutrientes contidos no meio. As proporções de inoculante utilizadas foram: 1, 3, 5 e $10 \%$. As plantas-testemunhas $(0 \%)$ foram produzidas da mesma forma, porém com ausência de inoculante no substrato do plantio.

O plantio foi efetuado após a distribuição do substrato nos tubetes e umidificação com água destilada. Foram empregadas sementes pré-germinadas, na proporção de 3-4 sementes por tubete, colocadas cerca de $1 \mathrm{~cm}$ abaixo da superfície do substrato. Após duas semanas, foi feito o desbaste, deixando-se somente uma planta por tubete.

$\mathrm{O}$ experimento constou de um delineamento inteiramente casualizado, com cinco tratamentos (quatro concentrações do inoculante + testemunha não-inoculada), com 24 repetições (plantas) por tratamento. As plantas foram mantidas em casa de vegetação, sob condições controladas de temperatura $\left(25 \pm 2^{\circ} \mathrm{C}\right)$. A umidade do substrato foi assegurada pela adição diária de água destilada.

Após 100 dias, as plantas foram colhidas, determinando-se a altura e o diâmetro do caule. Em seguida, o sistema radicular foi separado da parte aérea e dividido em duas partes, que foram pesadas para determinação do 
peso de matéria fresca. Uma das partes foi colocada em FAA (formalina-aceto-álcool, 9:1:1, v/v/v) e utilizada para determinação da porcentagem de colonização ectomicorrízica (amostra 1). A outra parte do sistema radicular (amostra 2), juntamente com a parte aérea, foi secada em estufa a $75^{\circ} \mathrm{C}$, até peso constante, para determinação do peso da matéria seca. O peso de matéria seca do sistema radicular foi calculado tomando-se como base o peso de matéria seca da amostra 2 e o peso de matéria fresca das duas amostras.

$\mathrm{O}$ conteúdo de $\mathrm{P}$ nos tecidos foi determinado pela digestão por via úmida com $\mathrm{H}_{2} \mathrm{SO}_{4}$ e $\mathrm{H}_{2} \mathrm{O}_{2}$ e leitura pelo método vanadato-molibdato, em espectrofotômetro $(660 \mathrm{~nm})$, conforme o método descrito por Tedesco et al. (1995), e os valores foram transformados em $\mathrm{mg}$ de P planta ${ }^{-1}$.

Para quantificar a intensidade de colonização micorrízica, utilizou-se o método das intersecções descrito por Giovanetti \& Mosse (1980). Para isso, a amostra do sistema radicular foi cortada em secções de aproximadamente $2 \mathrm{~cm}$, e depositada em placa de Petri $(\varnothing=9 \mathrm{~cm})$ com a superfície reticulada em quadrados de $1 \mathrm{~cm}^{2}$, e observada em microscópio estereoscópico (30 X). Foram observados todos os pontos de intersecção das raízes com as linhas da placa, anotando-se a presença ou ausência de raízes colonizadas num total de 1.000 pontos de intersecção por amostra.

Os dados foram submetidos a análise de variância, e a influência da dose de inóculo na intensidade de colonização radicular (\%), na produção de matéria seca (parte aérea, raiz, total e relação $\mathrm{R} / \mathrm{S}$ ), no teor de $\mathrm{P}$, na altura e diâmetro, foi avaliada pelo teste de Tukey $(\mathrm{p} \leq 0,05)$.

\section{Resultados e Discussão}

A porcentagem de colonização ectomicorrízica nas plantas dos tratamentos de inoculação variou entre
27 e $40 \%$, sendo maior nos tratamentos que receberam maior dose de inoculante (5 e 10\%) em relação aos demais tratamentos. Não foi observada colonização micorrízica nas plantas do tratamento-testemunha (Tabela 1).

As micorrizas corresponderam morfologicamente às que foram formadas por fungos do gênero Pisolithus, em outros estudos (Massicotte et al., 1987; Burgess et al., 1994), e apresentaram manto espesso, de cor amarelo-ferrugem, abundante micélio extra-radicular na forma de cordões e rizomorfas, estendendo-se no substrato, formando intensa massa de hifas na superfície interna dos tubetes.

A inoculação do fungo ectomicorrízico (UFSCPt24) promoveu aumentos nas variáveis avaliadas. A intensidade dos efeitos foi influenciada pela porcentagem de colonização ectomicorrízica, que, por sua vez, foi influenciada pela concentração do inoculante no substrato de plantio (Tabela 1). Assim, os maiores valores de matéria seca da parte aérea foram observados nas plantas do tratamento contendo $10 \%$ de inoculante, com $1,07 \mathrm{~g}_{\text {planta }}{ }^{-1}$. As plantas deste tratamento foram $67 \%$ superiores às plantas do tratamento-testemunha. Nas concentrações de 5\% e $3 \%$ de inoculante, os teores de matéria seca da parte aérea foram cerca de $62 \%$ superiores aos da testemunha. As plantas submetidas à inoculação da dose de $1 \%$ não diferiram das plantas-testemunhas em relação a este parâmetro.

Com relação à matéria seca das raízes, todos os tratamentos de inoculação apresentaram médias superiores à das plantas-testemunhas, e obtiveram-se aumentos da ordem de $84 \%$ no tratamento com $10 \%$ de inoculante, $56 \%$ no tratamento com $5 \%$ de

Tabela 1. Colonização micorrízica, conteúdo de fósforo (P) e crescimento de mudas de E. dunnii em presença de inoculante do fungo ectomicorrízico Pisolithus sp. (isolado UFSC-Pt24), produzido por fermentação semi-sólida, após 100 dias de crescimento em casa de vegetação. Média de 24 repetições $^{(1)}$.

\begin{tabular}{|c|c|c|c|c|c|c|c|c|}
\hline \multirow{2}{*}{$\begin{array}{c}\text { Inóculo } \\
(\%)\end{array}$} & \multirow{2}{*}{$\begin{array}{c}\text { Colonização } \\
(\%)\end{array}$} & \multirow{2}{*}{$\begin{array}{c}\mathrm{P} \\
\left(\mathrm{mg} \mathrm{pl}^{-1}\right)\end{array}$} & \multicolumn{3}{|c|}{ Matéria seca $\left(\mathrm{g} \mathrm{planta}^{-1}\right)$} & \multirow[t]{2}{*}{$\mathrm{R} / \mathrm{PA}^{(2)}$} & \multirow{2}{*}{$\begin{array}{l}\text { Altura } \\
(\mathrm{cm})\end{array}$} & \multirow{2}{*}{$\begin{array}{l}\text { Diâmetro } \\
(\mathrm{cm})\end{array}$} \\
\hline & & & Parte aérea & Raiz & Total & & & \\
\hline 0 & $0 \mathrm{c}$ & $0,46 \mathrm{~b}$ & $0,64 b$ & $0,25 b$ & $0,88 \mathrm{~b}$ & $0,39 b$ & $19,6 \mathrm{c}$ & $0,18 \mathrm{c}$ \\
\hline 1 & $29 b$ & $0,78 \mathrm{ab}$ & $0,72 b$ & $0,38 \mathrm{a}$ & $1,11 \mathrm{~b}$ & $0,55 \mathrm{a}$ & $22,5 b$ & $0,22 b$ \\
\hline 3 & $27 b$ & $0,89 \mathrm{ab}$ & $1,04 \mathrm{a}$ & $0,38 \mathrm{a}$ & $1,42 \mathrm{a}$ & $0,39 b$ & $26,2 \mathrm{a}$ & $0,25 \mathrm{a}$ \\
\hline 5 & $35 \mathrm{ab}$ & $0,98 \mathrm{a}$ & $1,03 \mathrm{a}$ & $0,39 \mathrm{a}$ & $1,42 \mathrm{a}$ & $0,40 \mathrm{~b}$ & $25,5 \mathrm{a}$ & $0,24 \mathrm{ab}$ \\
\hline 10 & $40 \mathrm{a}$ & $1,06 \mathrm{a}$ & $1,07 \mathrm{a}$ & $0,46 \mathrm{a}$ & $1,53 \mathrm{a}$ & $0,46 a b$ & $25,1 \mathrm{ab}$ & $0,23 \mathrm{ab}$ \\
\hline
\end{tabular}

(1) Em cada coluna, médias seguidas da mesma letra não diferem entre si a 5\% de probabilidade pelo teste de Tukey. (2) R/PA: relação raiz/parte aérea (peso de matéria seca de raiz/peso de matéria seca da parte aérea). 
inoculante, e $52 \%$ nas concentrações de $3 \%$ e $1 \%$, em relação ao tratamento-testemunha.

A relação raiz/parte aérea (R/PA), entretanto, foi pouco influenciada pela inoculação, e apenas na dose de $1 \%$ do inoculante foi significativamente superior à testemunha. Tem sido amplamente aceita a idéia de que a relação R/PA aumenta com a presença do fungo na raiz, em decorrência do maior crescimento desta. Entretanto, Dosskey et al. (1992) observaram que, na maioria dos casos, essa relação diminui com a colonização micorrízica, e que os aumentos são exceções resultantes da contribuição da biomassa fúngica para o peso final da raiz, que seria de cerca de $40 \%$, o que poderia representar $8 \%$ da biomassa total da raiz. Diminuição da relação R/PA em raízes colonizadas foi observada por Guehl et al. (1990).

Quanto à altura das plantas e ao diâmetro do colo, também houve efeito positivo da inoculação, em todos os tratamentos de inoculação com valores superiores aos das plantas-testemunhas.

A inoculação micorrízica favoreceu, também, a absorção de $\mathrm{P}$ na parte aérea $\left(\mathrm{mg} \mathrm{planta}^{-1}\right)$, principalmente nas doses de 5\% e 10\% do inoculante, onde as plantas apresentaram conteúdos superiores aos observados nas plantas-testemunhas. Os valores observados estão dentro do intervalo obtido por Bougher et al. (1990) em plantas de E. diversicolor que receberam inóculo com diferentes fungos ectomicorrízicos.

O maior acúmulo de $\mathrm{P}$ nas plantas que receberam inoculação $\left(\mathrm{mg} \mathrm{planta}^{-1}\right)$ reflete, a princípio, o maior crescimento destas. Entretanto, quando os teores de $\mathrm{P}$ são considerados em relação ao peso da matéria seca de raiz, verifica-se que a inoculação micorrízica proporcionou maior absorção de $\mathrm{P}$ pelas plantas. As plantas dos tratamentos 3, 5 e 10\% de inoculante apresentaram uma taxa de absorção variando de 2,3 a 2,51 mg de $\mathrm{P} \mathrm{g}^{-1}$ de raiz, contra $1,84 \mathrm{mg}_{\mathrm{ge}} \mathrm{P} \mathrm{g}^{-1}$ de raiz das plantas não submetidas a inoculação, evidenciando a maior eficiência das raízes colonizadas na captação desse nutriente. Efeitos semelhantes foram observados por outros autores em Eucalyptus spp. submetidos a inóculos com fungos ectomicorrízicos (Bougher et al., 1990; Oliveira et al., 1996).

$\mathrm{O}$ efeito da concentração do inoculante ectomicorrízico na colonização micorrízica e nos parâmetros de crescimento das plantas também foi observado por Hung \& Molina (1986), quando testaram o efeito de inoculante comercial, produzido pelo mesmo método, de três diferentes fungos (Hebeloma crustuliniforme, Laccaria laccata e Pisolithus tinctorius) em mudas de Pseudotsuga menziesii.

Estes resultados indicam que a colonização micorrízica teve influência positiva sobre os parâmetros de crescimento. Fica novamente evidenciada a influência da inoculação sobre a absorção de P pelas plantas, já observada por outros autores (Marx, 1980; Castellano \& Molina, 1989; Bougher et al., 1990; Thomson et al., 1994).

A forma de inoculação, pela mistura do inoculante com o substrato de plantio, também apresentou-se eficiente em promover a colonização e o crescimento das plantas. De acordo com Stenström (1990), a mistura homogênea do inoculante com o substrato permite uma melhor distribuição deste e uma colonização mais uniforme do sistema radicular do que outros métodos de inoculação, como, por exemplo, a aplicação em camadas, ou a inoculação de suspensões micelianas líquidas na superfície ou no interior do substrato.

Smith \& Read (1997) consideram que a adição de vermiculita ao meio de cultivo favorece a produção de biomassa fúngica, pois tal material representa um suporte particulado para proteção do micélio. Šašek (1990) também preconiza o uso de fermentação semisólida para a produção de inoculantes de fungos ectomicorrízicos. O processo apresenta uma série de vantagens em comparação com a clássica fermentação líquida; entre essas vantagens está a redução do volume de meio por massa de substrato. Embora o crescimento seja mais lento que na fermentação líquida, os riscos de contaminação por bactérias são menores, devido ao baixo teor de água livre.

É necessário, porém, testar a eficiência do inoculante na promoção do crescimento de plantas nos sistemas comerciais de produção de mudas do setor florestal, em viveiro e no campo. Também são necessários novos estudos para testar a eficiência do método de produção com outros fungos ectomicorrízicos selecionados, assim como a sobrevivência do inoculante durante o armazenamento. 


\section{Conclusões}

1. O inoculante do fungo Pisolithus sp. (isolado UFSC-Pt24), produzido por fermentação semi-sólida, apresenta compatibilidade (infectividade) e eficiência em relação ao Eucalyptus dunnii.

2. O inoculante apresenta potencial para promover a absorção de $\mathrm{P}$ e o crescimento das plantas de E. dunnii, com efeitos positivos a partir de $3 \%$ do inoculante na composição do substrato.

\section{Agradecimentos}

Ao PADCT (MCT), Subprograma de Biotecnologia (SBIO-01/95-02), pelo financiamento do trabalho; ao Programa RHAE-CNPq, pela bolsa de Desenvolvimento Tecnológico Industrial concedida ao primeiro autor; ao Prof. G. N. Silva Filho, MIP/UFSC, pela revisão do manuscrito.

\section{Referências}

ALVARENGA, R. M. Reserva legal e mudanças. Silvicultura, São Paulo, v. 55, p. 40-41, 1994.

BOUGHER, N. L.; GROVE, T. S.; MALAJCZUK, N. Growth and phosphorus acquisition of karri (Eucalyptus diversicolor B. Muell.) seedlings inoculated with ectomycorrhizal fungi in relation to phosphorus supply. New Phytologist, Cambridge, Grã-Bretanha, v. 114, n. 1, p. 77-85, 1990.

BURGESS, T.; DELL, B.; MALAJCZUK, N. Variation in mycorrhizal development and growth stimulation by 20 Pisolithus isolates inoculated on to Eucalyptus grandis W. Hill ex Maiden. New Phytologist, Cambridge, GrãBretanha, v. 127, n. 4, p. 731-739, 1994.

CASTELLANO, M. A.; MOLINA, R. Mycorrhizae. In: LANDIS, T. D.; TINUS, R. W.; McDONALD, S. E.; BARNETT, J. P. (Ed.). The biological components: nursery pests and mycorrhizae. In: ESTADOS UNIDOS. Department of Agriculture. The container tree nursery manual. Washington, 1989. p. 101-171.

DOMMERGUES, Y. R.; DIEM, H. G.; DIVIES, C. Polyacrylamide-entrapped Rhizobium as an inoculant for legumes. Applied and Environmental Microbiology, Washington, v. 37, n. 4, p. 779-781, 1979.
DOSSKEY, M. G.; LINDERMAN, R. G.; BOERSMA, L. Comparison of biomass in ectomycorrhizal and nonmycorrhizal Douglas fir seedlings of similar nutrition and overall size. Plant and Soil, Dordrecht, v. 142, p. 147150, 1992.

FRANK, B. Über die auf Wurzelsymbiose beruhende Ernährung gewisser Baume durch unterirdische Pilze. Berichte der Deutschen Botanischen Gesellschaft, Berlin, v. 3, p. 128-145, 1885.

GARBAYE, J. Competitivité des champignons ectomycorhiziens: premiers résultats et application à la sélection de souches pour la mycorhization contrôlée du hêtre et du chêne rouvre dans le nord-est de la France. Revue Forestière Française, Nancy, v. 36, n. 1, p. 33-43, 1984.

GARBAYE, J. Utilisation des mycorhizes en sylviculture. In: STRULLU, D. G. (Ed.). Les mycorhizes des arbres et plantes cultivées. Paris : Lavoisier, 1990. p. 197-250.

GIOVANETTI, M. G.; MOSSE, B. An evaluation of techniques for measuring vesicular-arbuscular mycorrhizal infection in roots. New Phytologist, Cambridge, GrãBretanha, v. 84, n. 3, p. 489-500, 1980.

GUEHL, J. M.; MOUSAIN, D.; FALCONET, G.; GRUEZ, J. Growth, carbon dioxide assimilation capacity and wateruse efficiency of Pinus pinea L. seedlings inoculated with different ectomycorrhizal fungi. Annales des Sciences Forestières, Paris, v. 47, p. 91-100, 1990.

HUNG, L. L.; MOLINA, R. Temperature and time in storage influence the efficacy of selected isolates of fungi in commercially produced ectomycorrhizal inoculum. Forest Science, Bethesda, v. 32, n. 2, p. 534-545, 1986.

KOPE, H. H.; FORTIN, J. A. Inhibition of phytopathogenic fungi in vitro by cell free culture media of ectomycorrhizal fungi. New Phytologist, Cambridge, GrãBretanha, v. 113, n. 1, p. 57-63, 1989.

KROPÁCEK, K.; CUDLÍN, P.; MEJSTRÍK, V. The use of granulated ectomycorrhizal inoculum for reforestation of deteriorated regions. Agriculture, Ecosystems and Environment, Amsterdam, v. 28, n. 1/4, p. 263-269, 1990.

KUEK, C.; TOMMERUP, I. C.; MALAJCZUK, N. Hydrogel bead inocula for the production of ectomycorrhizal eucalyptus for plantations. Mycological Research, Cambridge, Grã-Bretanha, v. 96, n. 4, p. 273-277, 1992.

LAST, F. T.; MASON, P. A.; WILSON, J. Controlled inoculation of sitka spruce with sheathing (ecto-) mycorrhizal fungi: a commercial experience in 1982. Scottish Forestry, Edinburgh, v. 38, n. 2, p. 75-77, 1984. LE TACON, F.; JUNG, G.; MUGNIER, J.; MICHELOT, P. Efficiency in a forest nursery of an ectomycorrhizal fungus 
inoculum produced in a fermented and entrapped in polymeric gels. Canadian Journal of Botany, Ottawa, v. 63, n. 9 , p. $1664-1668,1985$.

LEVY, Y.; KRIKUN, J. Effects of vesicular-arbuscular mycorrhiza on Citrus jambhiri water relations. New Phytologist, Cambridge, Grã-Bretanha, v. 85, n. 1, p. 2531, 1980.

LIMA, W. P. Impacto ambiental do eucalipto. São Paulo : Edusp, 1993. 302 p.

MARX, D. H. Ectomycorrhizal fungus inoculation: a tool for improving forest practices. In: MIKOLA, K. (Ed.). Tropical ectomycorrhiza research. Oxford : Clarendon, 1980. p. 13-71.

MARX, D. H. The influence of ectotrophic mycorrhizal fungi on the resistance of pine roots to pathogenic fungi and soil bacteria. I. Antagonism of mycorrhizal fungi to root pathogenic fungi and soil bacteria. Phytopathology, St. Paul, v. 59, p. 153-163, 1969.

MARX, D. H.; CORDELL, C. E.; MAUL, S. B.; RUEHLE, J. L. Ectomycorrhizal development on pine by Pisolithus tinctorius in bare-root and container seedlings nurseries. I. Efficacy of various vegetative inoculum formulations. New Forests, Dordrecht, v. 3, p. 45-56, 1989a.

MARX, D. H.; CORDELL, C. E.; MAUL, S. B.; RUEHLE, J. L. Ectomycorrhizal development on pine by Pisolithus tinctorius in bare-root and container seedlings nurseries. II. Efficacy of various vegetative and spore inocula. New Forests, Dordrecht, v. 3, p. 57-66, 1989b.

MARX, D. H.; RUEHLE, J. L.; KENNEY, D. S.; CORDELL, C. E.; RIFFLE, J. W.; MOLINA, R. J.; PAWUK, W. H.; NAVRATIL, S.; TINUS, R. W.; GOODWIN, O. C. Commercial vegetative inoculum of Pisolithus tinctorius inoculation techniques for the development of ectomycorrhizae on container-grow tree seedlings, Forest Science, Bethesda, v. 28, n. 2, p. 373-400, 1982.

MASSICOTTE, H. B.; PETERSON, R. L.; ASHFORD, A. E. Ontogeny of Eucalyptus pilularis - Pisolithus tinctorius ectomycorrhizae. I. Light microscopy and scanning electron microscopy. Canadian Journal of Botany, Ottawa, v. 65, p. 1927-1939, 1987.

MAUPÉRIN, C.; MORTIER, F.; GARBAYE, J.; LE TACON, F.; CARR, G. Viability of an ectomycorrhizal inoculum produced in a liquid medium and entrapped in a calcium alginate gel. Canadian Journal of Botany, Ottawa, v. 65, p. 2326-2329, 1987.

NEWSHAM, K. K.; FITTER, A. H.; WATKINSON, A. R. Multi-functionality and biodiversity in arbuscular mycorrhizas. Trends in Ecology and Evolution, Oxford, v. 10, n. 10, p. 407-411, 1995.

OLIVEIRA, V. L.; LAST, F. T.; MOHAN, V. Analyses of effects of mycorrhizal associations on growth of tree seedlings. In: AGUILAR, C.; BAREA, J. M. (Ed.). Mycorrhizas in integrated systems: from genes to plant development. Brussels : European Commission, 1996. p. 357-360.

PRADELLA, J. G. C.; ZUCCOLO, M.; LOPES, S. A. R.; OLIVEIRA, M. S. Pisolithus tinctorius vegetative mycelia production effects of nitrogen sources and cultivation in stirred tank fermenter. Revista de Microbiologia, São Paulo, v. 22, n. 1. p. 54-58, 1991.

ŠAŠEK, V. Submerged cultivation of ectomycorrhizal fungi. Agriculture, Ecosystems and Environment, Amsterdam, v. 28, n. 1/4, p. 441-447, 1990.

SMITH, S. E.; READ, D. J. Mycorrhizal symbiosis. London : Academic, 1997. 605 p.

SOCIEDADE BRASILEIRA DE SILVICULTURA (São Paulo, SP). ANPEC apresenta os números de 93. Silvicultura, São Paulo, v. 54, p. 10-11, 1994.

SOCIEDADE BRASILEIRA DE SILVICULTURA (São Paulo, SP). Luiz Kaufmann: setor não aproveita seu potencial. Silvicultura, São Paulo, v. 69, p. 7-11, 1997.

SOUZA, O. Contribuição ao estudo do cultivo de Pisolithus sp. Pt-24 por processo semi-sólido: influência da concentração inicial de glicose, temperatura de incubação e umidade do meio, sobre a produtividade do processo. São Paulo : USP, 1996. 137 p. Dissertação de Mestrado.

STENSTRÖM, E. The importance of infection methods and root environment on mycorrhiza formation. Agriculture, Ecosystems and Environment, Amsterdam, v. 28, n. $1 / 4$, p. $479-482,1990$.

TEDESCO, M. J.; GIANELLO, C.; BISSANI, C. A.; BOHNEN, H.; VOLKWEISS, S. J. Análise de solo, plantas e outros materiais. Porto Alegre : UFRGS, 1995. 174 p. THEODOROU, C.; BENSON, A. D. Operational mycorrhizal inoculation of nursery beds with seed-borne fungal spores. Australian Forestry, Yarralumla, v. 46, n. 1, p. 43-47, 1983.

THOMSON, B. D.; GROVE, T. S.; MALAJCZUK, N.; HARDY, G. E. S. J. The effectiveness of ectomycorrhizal fungi in increasing the growth of Eucalyptus globulus Labill. in relation to root colonization and hyphal development in soil. New Phytologist, Cambridge, GrãBretanha, v. 126, n. 3, p. 517-524, 1994.

WILKINS, D. A. The influence of sheathing (ecto-) mycorrhizas of trees on the uptake of metals. Agriculture, Ecosystems and Environment, Amsterdam, v. 35, n. 2/3, p. 245-260, 1991. 